E3S Web of Conferences 1, 40003 (2013)

DOI: $10.1051 / \mathrm{e} 3$ sconf $/ 20130140003$

(C) Owned by the authors, published by EDP Sciences, 2013

\title{
Low-Level Lead Exposure and Heart Rate Variability in Childhood: a Longitudinal Study
}

\author{
$\underline{\text { S. Tymchenko }}^{1}$ and E. Evstafyeva ${ }^{2}$ \\ ${ }^{1}$ Department of Physiology, State Institution Crimea State Medical University named after S. I. Georgievsky, UKRAINE, \\ rybqa@yahoo.com \\ ${ }^{2}$ Department of Physiology, State Institution Crimea State Medical University named after S. I. Georgievsky, UKRAINE, \\ e.evstafeva@mail.ru
}

\begin{abstract}
The objective of the present study was to assess whether small elevations in lead level were associated with measurable changes in autonomic cardiovascular regulation in urban children between 10 and 13 years old $(\mathrm{n}=30)$. Examinations at ages 10-11, 11-12 and 12-13 years included heart rate variability (HRV) and its time and frequency components. And lead concentrations were determined in the child's hair and based on its content children were considered to be leadexposed if their lead level was above $5 \mu \mathrm{g} / \mathrm{g}$. Results show that both time-domain (SDNN, RMSSD, pNN50) and frequency-domain (TP, HF) HRV parameters increased by about $20 \%$ from 10 to 13 years $(\mathrm{p}<0.001)$. Number of leadexposed children also significantly increased and by the age of 12 half of the study group had lead levels above $5 \mu \mathrm{g} / \mathrm{g}$. Content of lead in hair as biomarker of exposure was associated with a decrease in SDNN, TP, VLF, LF, LF/HF, LFn $(p<0.05)$ at age 12-13 years in nonexposed group, indicating decreased sympathetic (LF) and parasympathetic (SDNN) modulation of the HRV, which may be caused by underlying lead neurotoxicity at the central levels.
\end{abstract}

Key words: lead, heart rate variability, autonomic nervous system, children.

\section{Introduction}

Childhood lead poisoning continues to be a major public health problem and concerns remain over the effects of lead on central nervous system and intellectual development in infants and children since they are more vulnerable to lead exposure for three reasons: young children are more at risk of ingesting environmental lead through normal mouthing behaviors (Lanphear et al. 2002), absorption from the gastrointestinal tract is higher in children than adults (Ziegler et al. 1978), and the developing nervous system is thought to be far more vulnerable to the toxic effects of lead than the mature brain (Lidsky and Schneider 2003).

Although there appears to be no dispute about the effects of high levels of lead, there has been uncertainty about the effects of low levels of lead exposure on children's health. And lowering of exposure guideline levels reflects concern over the growing body of evidence that low levels of lead exposure have subtle effects on the nervous system of children. Since activity of sinus node pacemaker cells is under continuous regulation mainly effected by neural mechanisms the study of the heart rate variability can be used as a probe for the evaluation of its autonomic control and thus can be a possible marker of low-level lead exposure.

\section{Materials and Methods}

The study population consisted of thirty children living in urban area (Crimea, Ukraine). The following inclusion criteria were used for entry into the study: no known neurologic disorder, no severe chronic disease and taking no medication.

Lead exposure was assessed with a single hair specimen, using X-ray spectrophotometry (ElvaX-Med). Subjects were considered to be leadexposed if their lead level was above $5 \mu \mathrm{g} / \mathrm{g}$ and nonexposed if their lead level was between 0 and $4.99 \mu \mathrm{g} / \mathrm{g}$.

State of cardiovascular regulation was assessed through analysis of heart rate variability recorded by three-lead electrocardiography (Cardio, Ukraine) during 5-minute in supine position and standard time and frequency domain HRV parameters were obtained. Only normal-to-normal $(\mathrm{NN})$ beat intervals were used in the analysis. For the time domain, standard deviation of the 

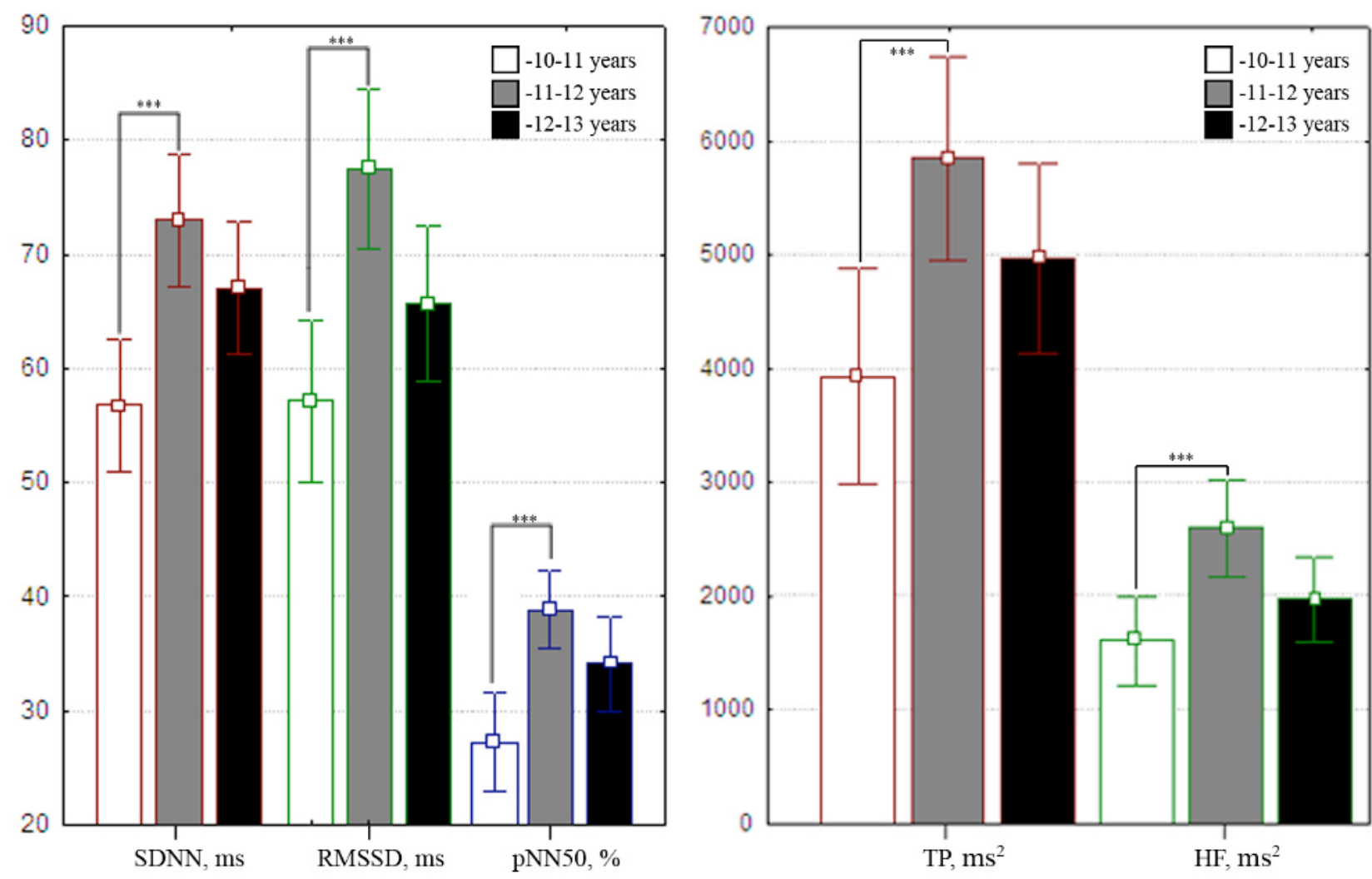

Fig. 2. HRV parameters at the age of 10-11, 11-12 and 12-13 years old.

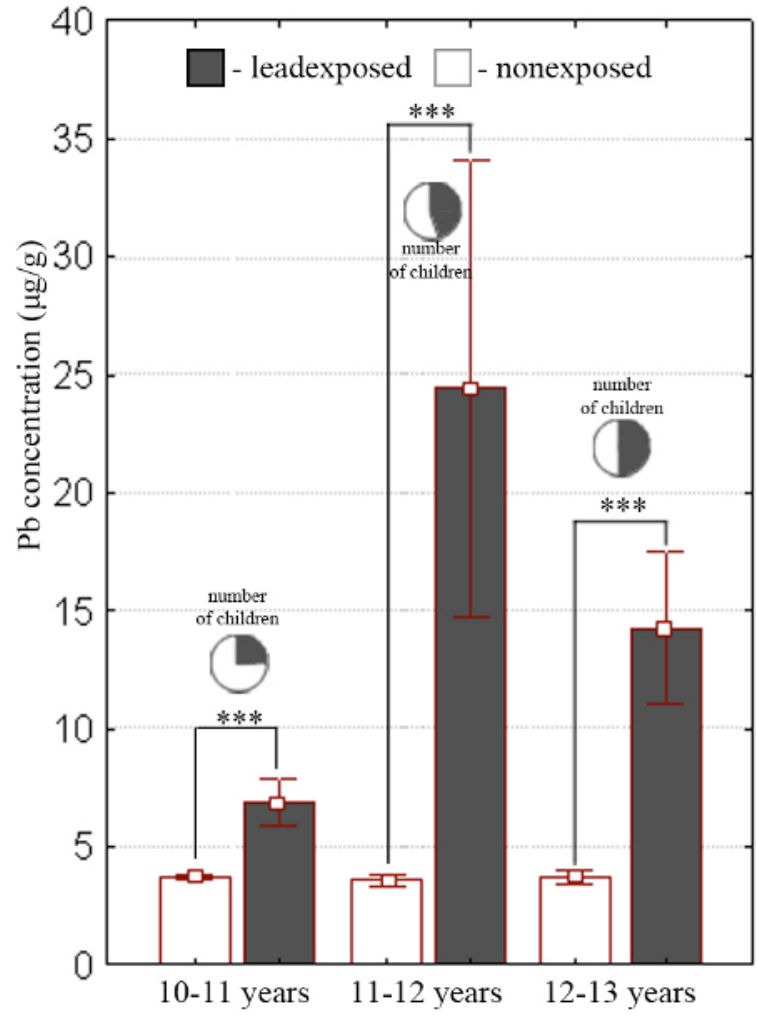

Fig. 1. Concentration of $\mathrm{Pb}$ in leadexposed and nonexposed children (10-13 year old) with number in each group.
$\mathrm{NN}$ intervals (SDNN), square root of the mean of the squared differences between adjacent normal R-R intervals (RMSSD) and mean number of times per hour in which the change in consecutive normal sinus (NN) intervals exceeds 50 milliseconds (pNN50) were measured. For the frequency domains, very low frequency (VLF, $\leq 0.04 \mathrm{~Hz}$ ), low frequency (LF, $0.04-0.15 \mathrm{~Hz}$ ), high frequency (HF, 0.15-0.4 Hz), total power $(\mathrm{TP}, \leq 0.4 \mathrm{~Hz}), \mathrm{LF} / \mathrm{HF}$ ratio, $\mathrm{LF}$ norm $(\mathrm{LF} / \mathrm{LF}+$ $\mathrm{HF})$, and HF norm (HF/LF + HF) were measured.

Lead and HRV assessment was made at the age of 10-11 years old and follow-up occurred 1 and 2 years later (11-12 and 12-13 years old respectively).

\section{Results and Discussion}

During first year 10-11 year old children in the leadexposed group $(n=7)$ had no significant difference in HRV parameters compared to that of children in the nonexposed group $(\mathrm{n}=23)$, with a mean lead levels (Fig. 1) twice as higher in first $(6.89 \pm 1.01 \mu \mathrm{g} / \mathrm{g}, \mathrm{p}<0.001$, Mann-Whitney U-test). During second year the number of leadexposed children increased $(n=14)$ with mean lead concentrations $24.43 \pm 9.68 \mu \mathrm{g} / \mathrm{g}$ compared to mean $(3.57 \pm 0.21 \mu \mathrm{g} / \mathrm{g})$ in nonexposed group $(\mathrm{p}<0.001$, Mann-Whitney U-test). In third year half of the children $(\mathrm{n}=15)$ were leadexposed with mean lead concentration $14.28 \pm 3.20 \mu \mathrm{g} / \mathrm{g}$ and in nonexposed it was $3.71 \pm 0.3 \mu \mathrm{g} / \mathrm{g}$ $(\mathrm{p}<0.001$, Mann-Whitney U-test). 
During the study period RRNN significantly increased, representing decrease in heart rate on about $11 \%$ at age of 13 years $(p<0.001)$. As figure 2 shows both time-domain (SDNN, RMSSD, pNN50) and frequency-domain (TP, HF) HRV parameters increased by about $20 \%$ from 10 to 13 years $(\mathrm{p}<0.001)$.

Even no significant difference were observed in HRV parameters in leadexposed and nonexposed children during these three years, but revealed negative associations by Spearmen analyses between $\mathrm{Pb}$ and SDNN, TP, VLF, LF, LF/HF, LFn and positive with HFn at the age of 12-13 years old in nonexposed group $\left(0.58<\mathrm{r}_{\mathrm{s}}<0.74, \mathrm{p}<0.05\right)$ suggest that lead may result in a reduction of VLF and LF spectral powers of HRV. Present study also shows that central cardiac modulation is inhibited and sympathetic activity is reduced.

\section{Conclusion}

These results suggests that lead determined in the child organism is only partially responsible for cardiac autonomic modulation and HRV parameters can be used as possible biomarkers of such exposure. Although cardiovascular variability is simultaneously influenced by several factors including behavioral stimuli, respiratory mechanics, neural influences, and humoral and endothelial substances, so further studies are needed to investigate the underlying mechanisms.

\section{References}

Lanphear BP, Hornung R, Ho M, Howard CR, Eberly S, Knauf K. Environmental lead exposure during early childhood. J Pediatr. 2002; 140:40-47.

Ziegler EE, Edwards BB, Jensen R1, Mahaffey KR, Fomon SJ. Absorption and retention of lead by infants. Pediatr Res. 1978; 12:29-34.

Lidsky TI, Schneider JS. Lead neurotoxicity in children: basic mechanisms and clinical correlates. Brain. 2003;126:5-19. 